\title{
Public Perspective on Increasing the Numbers of an Endangered Species, Loggerhead Turtles in South Korea: A Contingent Valuation
}

\author{
Ju-Hee Kim, Kyung-Ran Choi and Seung-Hoon Yoo *(D) \\ Department of Energy Policy, Graduate School of Energy \& Environment, Seoul National University of Science \\ and Technology, 232 Gongreung-Ro, Nowon-Gu, Seoul 01811, Korea; jhkim0508@seoultech.ac.kr (J.-H.K.); \\ krchoi@seoultech.ac.kr (K.-R.C.) \\ * Correspondence: shyoo@seoultech.ac.kr; Tel.: +82-2-970-6802
}

Received: 18 February 2020; Accepted: 4 May 2020; Published: 8 May 2020

check for updates

\begin{abstract}
The loggerhead turtle is one of the representative endangered marine species in South Korea. Thus, the country's government is trying to push ahead with a project to increase the number of loggerhead turtles through the research and development of technology to hatch them artificially and release them into the wild. This article attempts to investigate the public perspective on the project using contingent valuation (CV). To this end, a CV survey of one thousand households across the country was implemented using in-person interviews. They were asked whether they were willing to pay a specified amount presented for carrying out the project. As many households reported zero willingness to pay, a spike model was employed to analyze the response data. It was found that the yearly public value ensuing from accomplishing the project was statistically significantly computed to be KRW 2360 (USD 1.99) per household. When the value was expanded nationwide, it reached KRW 44.72 billion (USD 37.74 million) per year. This public value could be compared with the cost of carrying out the project to determine if the project is socially beneficial.
\end{abstract}

Keywords: public value; loggerhead turtle; endangered marine species; contingent valuation; willingness to pay

\section{Introduction}

Biodiversity is a major factor for assessing ecosystem health. The ocean, which occupies $71 \%$ of the Earth's surface area, is the largest living habitat. Accordingly, the world has made various efforts to preserve the diversity of marine ecosystem, such as conducting the Census of Marine Life. To preserve marine biodiversity, it is important to identify various marine species and preserve endangered species. In South Korea, to preserve the biodiversity of the marine ecosystem, the Korean Ministry of Oceans and Fisheries enacted the Act on Conservation and Management of Marine Ecosystems and designated seventy-seven endangered marine species in 2006 [1].

Sea turtles, which live in the tropical and subtropical ocean, travel thousands of kilometers every step of their lives to change their habitat, making it difficult to grasp the status quo. The current International Union for Conservation of Nature and Natural Resources Red List classifies four species, the Hawksbill turtle, the Kemp's ridley turtle, the green turtle, and the loggerhead turtle (Caretta caretta), as critically endangered group [2]. Among them, the loggerhead turtle is not only one of the endangered marine species, but is also on the Appendix I list of the Convention on International Trade in Endangered Species of Wild Fauna and Flora [3].

Among the various sea turtles living near South Korea, only the loggerhead turtle is known to lay eggs on the country's coast [4]. Therefore, the loggerhead turtle is the most likely species to 
have its population artificially increased. It has a reddish brown and long heart-shaped shell and eats fish, crustaceans, mollusks, jellyfish, and seaweed, as it is an omnivore. Although there are few predators of loggerhead turtles in the marine environment, their population is extremely small due to low breeding rates and incidents of turtle bycatches. In particular, the population has been declining significantly because sand beaches where the female turtles can scatter their eggs have been developed as breakwaters or beaches for leisure purposes $[5,6]$. Moreover, even if they can scatter their eggs on the beach, newborn baby turtles are exposed to a variety of threats. For instance, they may die because they lose their sense of direction due to artificial lighting installed on the beach [6].

The number of loggerhead turtles needs to be increased to restore the biodiversity of the marine ecosystem [7]. First of all, a variety of studies on how to increase the number of loggerhead turtles should be carried out. For example, studies on the restoration of their breeding ground, mating induction, and artificial hatcheries are needed. In particular, it is important to release hatched young loggerhead turtles from the artificial incubation site into the sea, as the loggerhead turtles tend to return to their natal beach where they hatched.

Thus, the government is trying to push ahead with a project of increasing the number of loggerhead turtles through the research and development of technology to hatch them artificially and release them into the wild. The implementation of the project requires considerable expenditure. This expenditure should be covered by taxes, which will be borne by the general public, who are taxpayers. Since public funds raised from taxes should be used in socially beneficial places, information about the public value of implementing the project is needed to determine whether the project is socially beneficial or not. If the public value exceeds the cost involved in the implementation, the implementation of the project can be justified, but if not, it is desirable that the project not be supported by the people and not be implemented. As such, the government is demanding that researchers should estimate the public value in increasing the number of loggerhead turtles.

For the purposes of meeting this demand, this study attempts to estimate the public value or benefits ensuing from increasing the number of loggerhead turtles by applying the contingent valuation (CV) method based on a nationwide survey of 1000 South Korean households. To this end, willingness to pay (WTP) responses were elicited from the interviewees employing the one-and-one-half-bounded (OOHB) dichotomous choice question format of asking an interviewee whether she/he is willing to pay a presented bid or not. Moreover, a spike model was adopted to deal with the WTP observations with a large number of zeros [8,9].

\section{Materials and Methods}

\subsection{Method: CV Technique}

The use of CV can assess public WTP for a service or good. The literature review, whose main findings are given in Table 1, implied that the CV approach has been widely applied to investigating the public perspective on increasing the number of endangered marine species or conserving them. For example, Samples and Hollyer [10], Whitehead [11], Loomis and Larson [12], Giraud et al. [13], Jin et al. [14], and Boxall et al. [15] dealt with people's WTP for preserving humpback whales and monk seals, the loggerhead turtle, the Steller sea lion, the marine turtle, and three marine mammal species, respectively, using the $\mathrm{CV}$ approach. Therefore, this article seeks to examine the public perspective on increasing the loggerhead turtles in South Korea using the CV technique. 
Table 1. Summary of the review of the literature dealing with endangered marine species.

\begin{tabular}{|c|c|c|c|c|}
\hline Sources & $\begin{array}{l}\text { Object to Be } \\
\text { Valued }\end{array}$ & Countries & Main Results & Method $^{a}$ \\
\hline Samples and Hollyer [10] & Humpback whale & United States & $\begin{array}{l}\text { USD } 239.53 \text { per household for avoiding } \\
\text { the loss of humpback whales }\end{array}$ & $\mathrm{CV}$ \\
\hline Samples and Hollyer [10] & Monk seal & United States & $\begin{array}{l}\text { USD } 165.80 \text { per household for } \\
\text { preserving the population of monk seals }\end{array}$ & $\mathrm{CV}$ \\
\hline Whitehead [11] & $\begin{array}{l}\text { Loggerhead } \\
\text { turtle }\end{array}$ & United States & $\begin{array}{l}\text { Overall, } 32 \% \text { of the respondents had } \\
\text { willingness to pay for the loggerhead } \\
\text { turtle protection program }\end{array}$ & $\mathrm{CV}$ \\
\hline Loomis and Larson [12] & Gray whale & United States & $\begin{array}{c}\text { USD } 23.65 \text { and } 26.53 \text { per household for } \\
50 \% \text { and } 100 \% \text { increases in whale } \\
\text { populations }\end{array}$ & CV \\
\hline Giraud et al. [13] & Steller sea lion & United States & $\begin{array}{l}\text { USD } 100.22 \text { per household for an } \\
\text { expanded federal protection program } \\
\text { for the Steller sea lion }\end{array}$ & $\mathrm{CV}$ \\
\hline Boxall et al. [15] & $\begin{array}{l}\text { Marine mammal } \\
\text { species }^{b}\end{array}$ & Canada & $\begin{array}{l}\text { USD } 77 \text { to } 229 \text { per household for } \\
\text { recovering the populations of three } \\
\text { marine mammal species }\end{array}$ & $\mathrm{CV}$ and $\mathrm{CE}$ \\
\hline Lim et al. [16] & Dokdo seal & South Korea & $\begin{array}{l}\text { USD } 4.86 \text { per household for } \\
\text { implementation of the Dokdo seal } \\
\text { restoration project }\end{array}$ & $\mathrm{CV}$ \\
\hline Cazabon-Mannette et al. [17] & Sea turtles & Tobago & $\begin{array}{l}\text { USD } 28.14 \text { to } 31.13 \text { per visitor for } \\
\text { conserving the sea turtles in Tobago }\end{array}$ & $\mathrm{CV}$ \\
\hline
\end{tabular}

Notes: ${ }^{a} \mathrm{CV}$ and $\mathrm{CE}$ indicate contingent valuation and choice experiment, respectively. ${ }^{\mathbf{b}}$ Included mammals such as beluga whale, harbor seals, and blue whale.

It is quite difficult to estimate the demand function for a good that is not traded on the market. Such goods are referred to as non-market goods. In the case of non-market goods, the data used to obtain the demand function are not available because there are no data on the transaction of the goods in the market [18]. According to microeconomic theory, the demand function implies a marginal WTP function, and a lower area of the demand function means WTP $[19,20]$. In fact, when dealing with non-market goods, we often need information about the upper area of the demand function, i.e., the benefits from the consumption of non-market goods or the economic value provided by non-market goods, rather than the demand function itself [21]. The methods applied to get that information are largely divided into the revealed preference (RP) approach and stated preference (SP) approach [22].

The RP approach observes and analyzes the results of a person's behavior as an ex-post technique. On the other hand, the SP approach examines the data obtained after asking people about preferences as an ex-ante technique. The two approaches have their own advantages and disadvantages; however, in theory, the SP approach is known to be more accurate, and the RP approach is limited in terms of the range of the objects to be assessed [23]. Therefore, judging from the literature, there were more studies that have applied the SP approach than those that have utilized the RP approach.

Two methods that have been widely used in empirical literature among SP methods are discrete choice experiments (CE) and CV. The CE method asks the respondents to evaluate value trade-offs among some attributes and is often applied to a good with multiple attributes $[24,25]$. The CV method is applied to single-attribute goods [26-31]. The term "contingent" means a situation where potential consumers of a non-market good are drawn into a hypothetical market in which the non-market goods can be recognized as being traded and then place a value on the goods [23]. Thus, it is necessary to clearly define the current state of reference and the target state to be valued in order to apply the CV method [32]. In addition, the process of collecting data through a survey is essential to the application of the CV method. For this reason, understanding the survey methodology, as well as familiarity with microeconomic theory are important in the application of the CV method [33].

In particular, Arrow et al.'s [34] paper referred to as the Blue Ribbon Panel Report of CV provided methodological guidance that applied CV research should follow, such as for example: the use of at least 1000 observations, the performance of in-person face-to-face interviewing instead of mail, 
telephone, or Internet interviews during a survey, the presentation of a description of some substitutes to the goods to be valued in the questionnaire, and the use of WTP rather than willingness to accept. Moreover, Johnston et al. [35] discussed guidelines to follow when applying the SP method including $\mathrm{CV}$. As will be explained below, this study tried to follow most of these guidelines.

\subsection{Survey Questionnaire and Field Survey}

The first step in creating a survey questionnaire is to define the goods to be evaluated accurately. This requires identifying the current state $\left(Q_{0}\right)$ and the target state $\left(Q_{1}\right)$ and clarifying the various policy measures for moving from the current state to the target state. In this study, the current state meant the state in which no additional action is taken by the government. Target status refers to the goal for which the government wants to take action and reach, that is to evaluate ultimately. Thus, the goods under evaluation indicate the difference between the target state $\left(Q_{1}\right)$ and the current state $\left(Q_{0}\right)$, rather than the target state $\left(Q_{1}\right)$ itself. In other words, the difference between do-something and do-nothing is assessed in the applied CV study. In this study, the current state was to do nothing to increase the number of loggerhead turtles, and the target state was to increase the number of loggerhead turtles through the research and development of technology, such as artificial incubation, and releasing them into the wild. Specifically, the target state was to release about five loggerhead turtles each year from 2025, after sufficient research on loggerhead turtles. This was because it takes a great deal of research to increase the number of loggerhead turtles, and since most of the beaches have already been developed in South Korea, it takes a considerable amount of time to secure the scattered land of loggerhead turtles.

The questionnaire consisted of three main parts. The first part slowly drove respondents to the hypothetical market, asking about the general perception and experience associated with the goods being evaluated. The second part described the current state, the target state, and the policy measures for moving from the current state to the target state and then asked the respondents about their WTP. The last part asked them about the socioeconomic characteristics of the respondent and the respondent's household, such as education level, income level, age, and gender. The initial version of the questionnaire should be checked for readability, and thus, this study refined it using a 30 member pre-survey focus group. In other words, final corrections to the questionnaire were made by checking whether there was anything that was difficult to understand or whether there was anything unclear.

In addition, based on the proposal of Hanemann and Kanninen [36], the range of bid amount for the dichotomous-choice (DC) WTP questions was refined using the results of a pre-test in a focus group. In other words, seven bid amounts were set within the range of $15 \%$ to $85 \%$ of the WTP distribution obtained as a result of the pre-survey. The respondents were randomly assigned to seven subgroups, with each sub-sample being asked to respond to a different set of bids (in Korean won). The set of bids used in this study were: $(1000,3000),(2000,4000),(3000,6000),(4000,8000),(6000,10,000),(8,000$, $12,000)$, and $(10,000,15,000)$, where the first element of each set corresponds to the lower bid and the second element corresponds to the upper bid.

The survey method must be determined for the field survey. Usually, four types of postal surveys, telephone surveys, person-to-person interviews, and Internet surveys are utilized. While postal surveys have low cost advantages, the response rate is relatively low in South Korea, and the sample may be biased to one side because only respondents with a particular propensity can respond.

For telephone surveys, the cost is reasonable, and random dialing methods, including mobile phones, allow for random sampling. However, it is difficult to present enough information to respondents to create a hypothetical market. More and more affordable Internet surveys are being conducted these days as Internet penetration increases, but there is a high possibility of obtaining a selected sample rather than a random one. Person-to-person interviews have the disadvantage of high cost, but it has the advantage of being able to take a random sample, fully presenting the information needed to immerse in the hypothetical market. Furthermore, the respondents can give answers conveniently through skilled professional interviewers. Therefore, this study employed person-to-person interviewing. 
Stratified random sampling was commissioned by sampling experts who were affiliated with a professional polling firm. More specifically, the sampling was performed through three steps. First, since there are sixteen major provinces across the country, a total of sixteen regions or strata were set up. Second, the 1000 observations to be collected were allocated to each stratum in proportion to the number of households in the population presented in the census implemented by Statistics Korea, the South Korean National Statistical Office, in 2015. Third, the professional polling firm randomly drew the allocated size of the sample within each stratum reflecting some of the characteristics of the population given in the census. The CV survey was conducted based on a structured questionnaire in October 2016.

\subsection{How to Elicit WTP Responses}

There have been four main types of question methods for eliciting WTP in the applied CV research literature. Typically, they are the open-ended question method, payment card method, bidding game method, and closed-ended question method. First, the open-ended question method can make interviewees become perplexed or strategically answer by directly asking for the WTP values. Second, the payment card method can help interviewees easily reveal their WTP by providing them with several payment cards that contain a list and level of conventional expenditures. Since this method essentially does not differ significantly from the open-ended question method, it can also suffer from strategic bias. Third, similar to an auction, the bidding game method provides interviewees with a specific value and then finds a particular converged value through continuing to ask subsequent questions. However, the converged value may suffer from starting point bias. Fourth, the closed-ended question method asks each respondent to accept or reject a suggested bid. The closed-ended question method has some merits, such as apparent incentive compatibility and the high degree of elimination of protest bids. This is because it asks an interviewee about whether she/he has the intention of paying a presented bid, and thus, it is quite simple and incentive-compatible to answer [23]. Therefore, the closed-ended question format was applied in this study.

Usually, the closed-ended question format includes the single-bounded (SB) question format proposed by Hanemann [37], the double-bounded (DB) question format suggested by Hanemann et al. [38], and the OOHB question format given by Cooper et al. [39]. The SB question format has the advantage of ensuring consistency, but the disadvantage of causing low efficiency. The DB question format, on the other hand, can achieve high efficiency, but result in low consistency [40,41]. This study applied the OOHB question format, which is most recently proposed among the three formats. The OOHB question format is known to achieve as much statistical efficiency as the double-bounded question format and enjoy as much consistency as the single-bounded question format [39].

For the application of the OOHB model, sets of two bid amounts must be established in advance: a lower bid amount $\left(T^{L}\right)$ and a higher bid amount $\left(T^{H}\right)$. The lower amount $\left(T^{L}\right)$ is first presented to approximately half of the interviewees, who are then asked if they have the intention of paying the amount. If "yes" is answered, interviewees are asked if they have the intention of paying the higher amount $\left(T^{H}\right)$. If "no" is responded, a follow-up question is not asked. The other interviewees are first asked if they have the intention of paying the higher amount $\left(T^{H}\right)$. If they respond "yes," they have no additional questions. However, if they report "no," they are further asked if they have the intention of paying the lower amount $\left(T^{L}\right)$. Thus, there is a total of six possible cases.

When the lower bid $\left(T^{L}\right)$ is presented first,

(i) If the response is "no," WTP $\leq T^{L}$;

(ii) If the response is "yes-no," $T^{L}<W T P \leq T^{H}$;

(iii) If the response is "yes-yes," $T^{H}<W T P$.

When the higher bid $\left(T^{H}\right)$ is presented first,

(iv) If the response is "no-no," WTP $\leq T^{L}$;

(v) If the response is "no-yes," $T^{L}<W T P \leq T^{H}$; 
(vi) If the response is "yes," $T^{H}<W T P$.

The binary variables representing the six cases can be defined as:

$$
\left\{\begin{array}{c}
B_{r}^{N}=I(r \text { th interviewee answers no }) \\
B_{r}^{Y N}=I(r \text { th interviewee answers "yes-no" }) \\
B_{r}^{Y Y}=I(r \text { th interviewee answers "yes-yes" }) \\
B_{r}^{N N}=I(r \text { th interviewee answers "no-no" }) \\
B_{r}^{N Y}=I(r \text { th interviewee answers "no-yes" }) \\
B_{r}^{Y}=I(r \text { th interviewee answers "yes" })
\end{array}\right.
$$

where $I(\cdot)$ has a value of one if the argument is true and zero if the argument is false.

\subsection{Econometric Model for Analyzing the WTP Responses}

The spike model is useful when dealing with closed-ended CV data with many zero values $[8,9]$. Therefore, this article adopted the OOHB spike model to analyze the WTP responses with zero observations. For the purpose of identifying respondents with $\mathrm{WTP}=0$, the interviewers further asked those who responded "no" to the lower amount $\left(T^{L}\right)$ whether they had the intention of paying anything or nothing, i.e., the WTP was greater than zero or zero. Two binary variables indicating possible outcomes concerning the further question were:

$$
\left\{\begin{array}{l}
B_{r}^{T Y}=I(r \text { th interviewee answers "yes" to the further question }) \\
B_{r}^{T N}=I(r \text { th interviewee answers "no" to the further question })
\end{array}\right.
$$

Therefore, there were eight possible cases.

When the lower bid $\left(T^{L}\right)$ was presented first,

(i) If the response is "no-no," WTP $=0$;

(ii) If the response is "no-yes," $0<\mathrm{WTP} \leq T^{L}$;

(iii) If the response is "yes-no," $T^{L}<\mathrm{WTP} \leq T^{H}$;

(iv) If the response is "yes-yes," $T^{H}<$ WTP.

When the higher bid $\left(T^{H}\right)$ was presented first,

(v) If the response is "no-no-no," WTP = 0;

(vi) If the response is "no-no-yes," $0<\mathrm{WTP} \leq T^{L}$;

(vii) If the response is "no-yes," $T^{L}<\mathrm{WTP} \leq T^{H}$;

(viii) If the response is "yes," $T^{H}<$ WTP.

Let the cumulative distribution of WTP be $H_{W T P}(\cdot)$. Using the logistic function commonly used in the literature, $H_{W T P}(\cdot)$ can be specified as:

$$
H_{W T P}\left(T ; \phi_{1}, \phi_{2}\right)=\left\{\begin{array}{cc}
{\left[1+\exp \left(\phi_{1}-\phi_{2} T\right)\right]^{-1}} & \text { if } T>0 \\
{\left[1+\exp \left(\phi_{1}\right)\right]^{-1}} & \text { if } T=0 \\
0 & \text { if } T<0
\end{array}\right.
$$

where $\phi_{1}$ and $\phi_{2}$ are parameters to be estimated.

In particular, the probability that WTP is zero is called the spike. Therefore, $\left[1+\exp \left(\phi_{1}\right)\right]^{-1}$ corresponds to the spike. Combining the general equation that obtains the mean using the cumulative distribution function and Equation (3) enabled us to derive the mean WTP as $\left(1 / \phi_{2}\right) \ln \left[1+\exp \left(\phi_{1}\right)\right]$. In addition, one can generate an estimate of the total WTP for the entire population of the study area by multiplying the estimate per household by the number of households of the area. Let the bid amount presented to respondent $r$ be $T_{r}$. Thus, the lower and higher bids offered to respondent $r$ are expressed 
as $T_{r}^{L}$ and $T_{r}^{H}$, respectively, for $r=1, \cdots, R$. The log-likelihood function corresponding to the OOHB spike model is:

$$
\begin{aligned}
\ln L= & \sum_{r=1}^{R}\left\{\left(B_{r}^{Y Y}+B_{r}^{Y}\right) \ln \left[1-H_{W T P}\left(T_{r}^{H} ; \phi_{1}, \phi_{2}\right)\right]\right. \\
& +\left(B_{r}^{Y N}+B_{r}^{N Y}\right) \ln \left[H_{W T P}\left(T_{r}^{H} ; \phi_{1}, \phi_{2}\right)-H_{W T P}\left(T_{r}^{L} ; \phi_{1}, \phi_{2}\right)\right] \\
& +B_{r}^{T Y}\left(B_{r}^{N}+B_{r}^{N N}\right) \ln \left[H_{W T P}\left(T_{r}^{L} ; \phi_{1}, \phi_{2}\right)-H_{W T P}\left(0 ; \phi_{1}, \phi_{2}\right)\right] \\
& \left.+B_{r}^{T N}\left(B_{r}^{N}+B_{r}^{N N}\right) \ln H_{W T P}\left(0 ; \phi_{1}, \phi_{2}\right)\right\}
\end{aligned}
$$

One can obtain the maximum likelihood estimates for $\phi_{1}$ and $\phi_{2}$ by maximizing Equation (4) with respect to $\phi_{1}$ and $\phi_{2}$. The variables representing the respondents' characteristics are called covariates. The model including covariates can be utilized to look into the impact of the covariates on the probability that they would respond "yes" to the proposed bid amount. Replacing $\phi_{1}$ with $\phi_{1}+y_{r}^{\prime} \omega$ in Equations (3) and (4) gives us the model with covariates where $y_{r}$ and $\omega$ are vectors of covariates and coefficients matching with the covariates, respectively.

Since an estimate of mean WTP is usually utilized for policy analysis or evaluation, it is necessary to compute and present a confidence interval (CI) to reflect the uncertainties that may arise during the estimation of mean WTP. The parametric bootstrap technique given in Krinsky and Robb [42] was used in this study. This included sampling $\phi_{1}$ and $\phi_{2} 5000$ times from the bivariate normal distribution of the estimated coefficients for $\phi_{1}$ and $\phi_{2}$, computation of 5000 mean WTPs for sampled $\phi_{1}$ and $\phi_{2}$, sorting them to obtain the empirical distribution of mean WTP, and finding the CI from the empirical distribution.

\subsection{Data}

As explained above, it is necessary to take the utmost care in collecting data through a CV survey. In this regard, four important considerations were taken into account in this study.

- First, the sample size was set at 1000. This was because Arrow et al. [34] proposed 1000 as the number of observations needed for policy decision-making, and the Korean Ministry of Strategy and Finance and the Korea Development Institute, a government-run think tank, have also provided a guideline on the size of a nationwide sample needed for policy decision-making as 1000 .

- Second, we tried to make certain the representativeness of the sample by implementing sampling based on the census data gathered in 2015 by Statistics Korea. As individual estimates of mean WTP have been derived, we could estimate aggregate benefits, which Arrow et al. [33] identified as one of the significant issues in using CV results. When expanding the sample to the population, one critical concern is the representativeness of the sample. In this regard, a comparison of the characteristics of the sample with those of the population is reported in Table 2. It can be seen that there was not much difference between the values for the sample and those for the population.

- Third, a professional polling firm was commissioned to conduct the CV survey to ensure fairness in sampling and implementing face-to-face surveys, despite its high cost.

- Fourth, we chose the yearly income tax as a payment vehicle to help respondents reveal their actual WTP without difficulty. In addition, the payment period presented in the CV survey was 10 years.

In summary, the data were drawn from a survey of 1000 households with members aged 20 to 65 years in October 2016 carried out by a professional survey firm located in Seoul, the capital of South Korea. Judging from the comments of the supervisor and interviewers who were affiliated with the company, the survey was conducted without difficulty and was successful enough to collect the opinions of respondents who could represent the population. 
Table 2. Sample characteristics.

\begin{tabular}{|c|c|c|}
\hline Variables & Sample ${ }^{a}$ & Population ${ }^{b}$ \\
\hline \multicolumn{3}{|l|}{ Gender } \\
\hline Female & $50.0 \%$ & $49.9 \%$ \\
\hline Male & $50.0 \%$ & $50.1 \%$ \\
\hline \multicolumn{3}{|l|}{ Region } \\
\hline Seoul & $19.8 \%$ & $19.1 \%$ \\
\hline Pusan & $6.8 \%$ & $6.7 \%$ \\
\hline Daegu & $4.7 \%$ & $4.8 \%$ \\
\hline Incheon & $5.5 \%$ & $5.7 \%$ \\
\hline Gwangju & $2.8 \%$ & $2.9 \%$ \\
\hline Daejeon & $2.8 \%$ & $3.0 \%$ \\
\hline Ulsan & $2.1 \%$ & $2.3 \%$ \\
\hline Sejong & $0.4 \%$ & $0.5 \%$ \\
\hline Gyunggi & $23.4 \%$ & $24.7 \%$ \\
\hline Gangwon & $3.3 \%$ & $3.0 \%$ \\
\hline Chungbuk & $3.2 \%$ & $3.1 \%$ \\
\hline Chungnam & $4.2 \%$ & $4.2 \%$ \\
\hline Jeonbuk & $3.7 \%$ & $3.6 \%$ \\
\hline Jeonnam & $4.0 \%$ & $3.5 \%$ \\
\hline Gyungbuk & $5.6 \%$ & $5.2 \%$ \\
\hline Gyungnam & $6.5 \%$ & $6.5 \%$ \\
\hline Jeju & $1.2 \%$ & $1.2 \%$ \\
\hline sehold income ${ }^{\mathrm{c}}$ & KRW 4.33 million & KRW 4.42 million \\
\hline
\end{tabular}

Notes: ${ }^{\text {a }}$ The number of respondents is $1000 .{ }^{b}$ Comes from Statistics Korea [43]. ${ }^{\mathrm{c}}$ Means the average.

The first column of Table 3 presents the bid amounts provided to the interviewees. The table also reports the distribution of the interviewees' responses to them. Each bid was offered to a similar number of interviewees. A total of 618 interviewees answered "no-no" or "no-no-no," and they said they were not willing to pay a single penny. This indicated that $61.8 \%$ of 1000 interviewees had zero WTP for increasing the population of loggerhead turtles. This finding implied that it was desirable for this study to employ a spike model and analyze WTP responses with zeros.

Table 3. Distribution of responses to presented bid amount.

\begin{tabular}{|c|c|c|c|c|c|c|c|c|c|c|}
\hline & & \multicolumn{4}{|c|}{ Lower Bid Is Given First (\%) ${ }^{b}$} & \multicolumn{4}{|c|}{ Higher Bid Is Given First (\%) ${ }^{b}$} & \multirow[b]{2}{*}{ Sample Size } \\
\hline \multicolumn{2}{|c|}{ Bid Amount ${ }^{\text {a }}$} & "yes-yes" & "yes-no" & "no-yes" & "no-no" & "yes" & "no-yes" & "no-no-yes" & "no-no-no" & \\
\hline 1000 & 3000 & $9(6.3)$ & 19(13.3) & $5(3.5)$ & $39(27.3)$ & $31(21.7)$ & $15(10.5)$ & $5(3.5)$ & $20(14.0)$ & 143(100.0) \\
\hline 3000 & 6000 & $11(7.7)$ & $10(6.9)$ & $5(3.5)$ & $45(31.5)$ & $11(7.7)$ & $8(5.6)$ & $11(7.7)$ & $42(29.4)$ & 143(100.0) \\
\hline 4000 & 8000 & $5(3.5)$ & 13(9.1) & $10(7)$ & $44(30.8)$ & $13(9.1)$ & $11(7.7)$ & $6(4.2)$ & $41(28.7)$ & 143(100.0) \\
\hline 6000 & 10,000 & $2(1.4)$ & 11(7.7) & $12(8.5)$ & $46(32.4)$ & $8(5.6)$ & $9(6.3)$ & $8(5.6)$ & $46(32.4)$ & $142(100.0)$ \\
\hline \multicolumn{2}{|c|}{ Totals } & $37(3.7)$ & $76(7.6)$ & $76(7.6)$ & $311(31.1)$ & $66(6.6)$ & $59(5.9)$ & $68(6.8)$ & $307(30.7)$ & $1000(100.0)$ \\
\hline
\end{tabular}

Notes: ${ }^{\text {a }}$ The units are Korean won. The exchange rate was USD 1 = KRW 1185 at the time of the survey. ${ }^{b}$ The percentage of the responses is reported in parentheses next to the number of respondents.

\section{Results}

\subsection{Estimation Results}

Table 4 shows the results from estimating the model. The estimated coefficients for the constant term and the bid amount were all statistically significant at a significance level of $1 \%$. Furthermore, the sign of the coefficient estimates for the bid amount was correctly negative. This implied that the bid amount had a negative correlation with the probability of saying "yes" to a suggested bid. The Wald statistic computed under the null hypothesis that all the parameter estimates were jointly zero was 432.76 , and its $p$-value was 0.000 . Thus, the hypothesis could be rejected at a significance level of $1 \%$. 
The estimate for the spike was 0.6166 , which was close to the sample proportion of 0.6180 and had statistical meaningfulness.

Table 4. Results from estimating the model.

\begin{tabular}{|c|c|}
\hline Variables & Coefficient Estimates ( $t$-Values) \\
\hline Constant & $-0.4751(-7.35)^{\#}$ \\
\hline Bid amount ${ }^{a}$ & $-0.2049(-17.33) \#$ \\
\hline Spike & $0.6166(40.37) \#$ \\
\hline Mean additional willingness to pay per household per year & KRW 2360 (USD 1.99) \\
\hline$t$-value & $14.69 \#$ \\
\hline $95 \%$ confidence interval ${ }^{b}$ & KRW 2066 to 2710 (USD 1.74 to 2.29 ) \\
\hline $99 \%$ confidence interval ${ }^{b}$ & KRW 1992 to 2834 (USD 1.68 to 2.39) \\
\hline Number of observations & 1,000 \\
\hline Log-likelihood & -1075.10 \\
\hline Wald statistic ( $p$-value $)^{b}$ & $432.76(0.000)$ \\
\hline
\end{tabular}

Notes: ${ }^{a}$ The units are Korean won. ${ }^{b}$ The confidence intervals are calculated using the method by Krinsky and Robb [42]. ${ }^{c}$ The null hypothesis is that all the parameters are jointly $0 .{ }^{\#}$ Commonly used for the significance level of $1 \%$.

The constant term included all other factors, except for the bid amount, that may have an effect on the probability of responding "yes" to a presented bid. Therefore, it was difficult to find any particular meaning in its magnitude, sign, or significance of the constant term where several factors were synthesized. From a statistical point of view, the constant term was essential in calculating the mean WTP that this study sought to derive since it was a parameter contained in the cumulative distribution function of WTP.

The estimated yearly mean additional WTP for increasing the population of loggerhead turtles was KRW 2360 (USD 1.99) $(t=14.69)$ per household. It was significantly different from zero at a significance level of $1 \%$. In addition, Table 4 contains the $95 \%$ and $99 \%$ CIs for the estimated mean WTP.

The model reported in Table 4 was without covariates. However, the effects of covariates related to the characteristics of respondents may be considered. That is, it was necessary to consider the impact of interviewees' characteristics on the likelihood of responding "yes" to the amount presented. This was because the $\mathrm{CV}$ data were derived from a survey of interviewees. In other words, the model containing covariates was estimated to assess whether theoretical validity or internal consistency with respect to the application of $\mathrm{CV}$ was satisfied or not. Information about the covariates used is summarized in Table 5. The results from estimating the model are given in Table 6.

Table 5. Basic information about the variables used for covariates.

\begin{tabular}{cccc}
\hline Variables & Definitions & Mean & Standard Deviation \\
\hline Gender & Interviewee's gender $(0=$ male; $1=$ female) & 0.50 & 0.50 \\
Education & $\begin{array}{c}\text { Interviewee's education level in years } \\
\text { Interviewee's households' income per } \\
\text { Income }\end{array}$ & 14.01 & 2.42 \\
& month (units: million Korean won) & 1.82 \\
\hline
\end{tabular}

A positive sign of the coefficient indicates that the variable had a positive correlation with the probability of responding "yes" to the given bid. If not, it suggests that it had a negative correlation. For example, the coefficients for the Education and Income variables were estimated to be positive. Therefore, the higher the level of education, the greater the probability of answering "yes" to the suggested bid. In addition, the higher the income level, the more likely "yes" was the response to the offered bid. 
Table 6. Estimation results of the spike model with covariates.

\begin{tabular}{|c|c|}
\hline Variables $^{\text {a }}$ & Coefficient Estimates ( $t$-Values) \\
\hline Constant & $-2.9831(-6.95)^{\#}$ \\
\hline Bid amount ${ }^{b}$ & $-0.2106(-18.02) \#$ \\
\hline Gender & $0.2575(1.98) \#$ \\
\hline Education & $0.1342(4.59) \#$ \\
\hline Income & $0.1094(3.04)^{\#}$ \\
\hline Spike & $0.6227(39.81)^{\#}$ \\
\hline Mean additional willingness to pay per household per year & KRW 2249 (USD 1.90) \\
\hline$t$-value & $14.84^{\#}$ \\
\hline $95 \%$ confidence interval ${ }^{c}$ & KRW 1985 to 2570 (USD 1.68 to 2.17 ) \\
\hline $99 \%$ confidence interval ${ }^{c}$ & KRW 1909 to 2695 (USD 1.61 to 2.27 ) \\
\hline Number of observations & 1,000 \\
\hline Log-likelihood & -1053.21 \\
\hline Wald statistic ( $p$-value $)^{\mathrm{d}}$ & $220.13(0.000)$ \\
\hline
\end{tabular}

Notes: ${ }^{a}$ The variable explained in Table $5 .{ }^{b}$ The units are Korean won. ${ }^{c}$ The confidence intervals are calculated using the method by Krinsky and Robb [42]. ${ }^{\mathrm{d}}$ The null hypothesis is that all the parameters are jointly $0 .{ }^{\text {\# Commonly }}$ used for the significance level of $5 \%$.

\subsection{Discussion of the Results}

The various CV empirical studies conducted in South Korea often encountered too many zero WTP responses $[16,26,44,45]$. Most of them were often classified as protest responses, for which reasons include: The question is too difficult to understand; the government is not confident in pursuing the proposed plan or project; the government is already spending too much money in this field; the person who caused the problem, not me, has to pay; I do not like this type of question at all; and this is not my concern [46]. In other words, protest responses meant rejection of the CV survey itself, making it difficult to view it as a reasonable response, and it was desirable to exclude it from the analysis [23]. However, this exclusion reduced the size of sample that was valid for the actual analysis. In this case, the need to analyze the data of which more than half had been discarded could not only diminish the usefulness of empirical CV studies, but also cause a bias if there was a structural difference in the socioeconomic characteristics between the protest respondents and the non-protest respondents [47]. There was a way to treat protest responses as zero WTP.

That is, this study judged that the 618 responses were not meaningless, but clearly meaningful and valid, and that they could be treated as zero WTP responses. In this regard, the study did not exclude all or part of the 618 responses from the final dataset to be analyzed. They were dealt with as zero WTP responses using the spike model, which could reflect explicitly zero WTP, as well as positive WTP responses. Therefore, the mean WTP estimate obtained from analyzing the spike model using a total of 1000 observations was considered reasonable in its use as information about the benefits ensuing from increasing the population of loggerhead turtles.

After obtaining the mean annual WTP for each household, the next step was to estimate aggregate values, that is to extend the value of the sample across the population, and what was important was the sample's representation. As explained earlier in this article, the CV surveys with 1000 people nationwide were conducted by skilled interviewers from a professional polling firm. Furthermore, as shown in Table 2, there were no significant gaps between the sample average for the variables and the population average for those. Therefore, the authors believed that this sample was representative and well balanced.

Since the whole sample may not be identical at the national level, segmenting and then analyzing the sample according to the sample characteristics could provide us with some interesting findings. In particular, different outcomes may be derived depending on the region of the respondents. However, the sample size adopted in this study was only 1000, and the segmentation may decrease the number of observations to be analyzed, thereby reducing the statistical efficiency. In addition, as described 
earlier, it was appropriate to expand it nationwide because the sample of this survey was selected through the national stratified sampling method.

One of the most important purposes of the applied CV study was to expand the location value of WTP obtained from the sample to the population. In this regard, we should determine which of the location values for the sample to use. Usually, the mean, median, and mode are used for the location value. The median WTP obtained in this study was zero, and the mean WTP was estimated to be positive. The mode WTP could not be computed because we used the DC WTP question. It was necessary to determine which of the mean or median to use. The median is known to be all the more robust than the mean because the mean is vulnerable to outliers, but the median is not. The median can be useful for identifying the central tendency of the sample, but it is not used for expanding a sample value to a population value because it can cause underestimation to overestimation in the expansion. Therefore, the mean WTP has been almost always employed in the literature when estimating the population value using the sample value.

As explained earlier, we conducted stratified random sampling using sixteen strata. The sample size allocated to each stratum was decided based on the Census implemented by Statistics Korea in 2015. In other words, the sample size of each stratum was consistent with the population. Thus, in this study, the total value was calculated by multiplying the mean WTP by the number of households in the population instead of using a mean formula applied for stratified sampling.

As the covariates may affect the mean WTP estimate, the mean WTP in Table 3 was used in expanding the value of the sample to the value of the population. By multiplying the mean WTP estimate per household by the total number of households in South Korea, we could generate the total WTP, expanded to the relevant population. When the survey was conducted, South Korea had $18,948,342$ households [43]. The population's total WTP for increasing the population of loggerhead turtle was KRW 44.72 billion (USD 37.74 million) per year, as shown in Table 7. The 95\% CI for the total public value was KRW 39.15 to 51.35 billion (USD 33.04 to 43.33 million). It seemed that policies increasing the population of loggerhead turtle contributed to South Korean households' utility.

Table 7. Estimation of total willingness to pay (WTP).

\begin{tabular}{ccc}
\hline & Estimates & $\mathbf{9 5 \%}$ Confidence Intervals \\
\hline $\begin{array}{c}\text { Mean additional WTP per } \\
\text { household per year }\end{array}$ & KRW 2360 & KRW 2066 to,710 \\
Total annual WTP & KRW 44.72 billion & (USD 1.74 to 2.29) \\
& (USD 37.74 million) & (USD 33.04 to 43.33 million) \\
\hline
\end{tabular}

Note: South Korea had 18,948,342 households at the time of the survey [43].

In terms of the object to be valued, Whitehead's [11] study was the most similar to this study. However, it was difficult to compare the findings directly from the two studies because this study differed from Whitehead's [11] study in six respects: payment vehicle, sample size, survey method, the time of the survey, the model, and estimated mean WTP. In addition, Whitehead [11] asked the respondents their subjective probabilities of supply and demand in the CV survey and included them in the analysis of the WTP model to investigate ex-ante WTP with supply and demand uncertainty. He found that both the coefficients for supply probability and demand probability were statistically significant at the $5 \%$ level and argued that subjective probabilities of supply and demand should be collected from the CV survey and reflected in the WTP model. Unfortunately, we did not include the questions about subjective probabilities of supply and demand in the CV questionnaire and thus could not implement the analysis given in Whitehead [11].

\section{Conclusions}

The South Korean government designated 77 endangered marine species to preserve the biodiversity of marine ecosystems, and the loggerhead turtle was one of them. This study intended to 
measure the public value of increasing the population of loggerhead turtle by applying a nationwide CV survey of 1000 South Korean households. The mean WTP for increasing the population of the loggerhead turtle was estimated to be KRW 2360 (USD 1.99) per household, per year. Converting this value to a WTP of the entire region through the number of households nationwide, it was computed to be KRW 44.72 billion (USD 37.74 million) per year. This value could be interpreted as the total WTP of the nation for increasing loggerhead turtles.

The results of this study were judged to be meaningful from the research perspective, as well as from the policy perspective. This study had two important policy implications. First, the amount of each household's WTP for increasing the population of loggerhead turtles was quantitatively assessed. Utilizing the results of this study, it was possible for us to evaluate the benefits of raising the population of loggerhead turtles from the current level to a higher level, coupled with values that could not be considered by market mechanisms. Following that, the total WTP of the nation for increasing the population of loggerhead turtles was quantitatively measured. As the public utilities plan to protect loggerhead turtles, it was required to perform an economic feasibility analysis. In doing so, the essential information as the publicized WTP from the national point of view. Second, it was found that $61.8 \%$ of households had no intention of making additional payments. In all, more than half of the households were judged to have a negative point of view of the project. This suggested that the government needs to persuade the public more actively and rationally to ensure a successful plan for increasing the species.

To the best of the authors' knowledge, there have not been many case studies that have applied $\mathrm{CV}$ to an endangered species, specifically loggerhead turtles. Thus, one purpose of this study was to add a case study of South Korea to the literature. In particular, the implications of this study are all the more useful because there have been no related studies for the country. Nevertheless, this study needs to be improved in several respects to ensure that it is distinct from previous studies. First, if more observations are obtained through additional budgeting, the respondents can be segmented, and the analysis could be made according to various criteria, such as the geolocation of the respondent, whether the respondent has knowledge of campaigns around the issue prior to the survey, and the relevance of the local issue, so as to obtain differentiated implications for each segmented group. For example, since regions that are adjacent to the coast are different from regions that are located inland, the consideration of the marine species can be different between the two types of regions.

Second, some or all of the covariates used in the model with covariates, such as education and income, could cause an endogeneity bias. If the bias occurs, the estimation results and/or the decision-making based on them can be distorted. Therefore, it is necessary to check whether the covariates used cause the bias, and if the bias exists, the bias must be rectified by adding the omitted variables to the model of covariates or by applying an instrument variable estimation method.

Third, when applying the CV method, it may be expected that respondents' awareness of the questionnaire will affect their WTP. It is necessary to look at how the awareness of the endangered marine species and marine life being studied affects the amount of WTP. Fourth, this study took a conservative approach that did not distinguish true zero WTP from a protest bid response and regarded both responses as zero WTP responses; however, it needs to be analyzed how the mean WTP estimate changes when taking other approaches. Fifth, the supply and demand uncertainty of the goods to be valued needs to be examined in future applied CV studies.

Author Contributions: All three authors had significant roles in planning and writing this note. J.-H.K. proposed the ideas for the paper, laid out the basic framework for the survey, and wrote half of the paper; K.-R.C. completed the final version of the questionnaire and analyzed the model using the collected data; and S.-H.Y. supervised the entire course of the research, wrote part of the paper, and refined the entire paper. All authors have read and agreed to the published version of the manuscript.

Funding: This research is part of the project entitled "Marine ecosystem-based analysis and decision-making support system development for marine spatial planning," funded by the Korean Ministry of Oceans and Fisheries (Grant Number 20170325).

Conflicts of Interest: The authors declare no conflict of interest. 


\section{References}

1. Korea Ministry of Oceans and Fisheries. Conservation and Management of Marine Ecosystems Act. Available online: http://www.mof.go.kr/eng/index.do (accessed on 3 February 2020).

2. International Union for Conservation of Nature. IUCN Red List of Threatened Species. Available online: https://www.iucnredlist.org/ (accessed on 3 February 2020).

3. Convention on International Trade in Endangered Species of Wild Fauna and Flora. The CITES Species. Available online: https://www.cites.org/eng/disc/species.php (accessed on 3 February 2020).

4. Korea Marine Environment Management Corporation. Species Increase and Restoration of Marine Endangered Species; Korea Marine Environment Management Corporation: Seoul, Korea, 2014. (In Korean)

5. Mazaris, A.D.; Matsinos, G.; Pantis, J.D. Evaluating the impacts of coastal squeeze on sea turtle nesting. Ocean Coast. Manag. 2009, 52, 139-145. [CrossRef]

6. Lutcavage, M.E. Human impacts on sea turtle survival. In The Biology of Sea Turtles; CRC Press: Boca Raton, FL, USA, 2017; Volume 1, pp. 387-409.

7. Lovich, J.E.; Ennen, J.R.; Agha, M.; Gibbons, J.W. Where have all the turtles gone, and why does it matter? BioScience 2018, 68, 771-781. [CrossRef]

8. Yoo, S.-H.; Kwak, S.-J. Using a spike model to deal with zero response data from double bounded dichotomous contingent valuation survey. Appl. Econ. Lett. 2002, 9, 929-932. [CrossRef]

9. Kriström, B. Spike models in contingent valuation. Am. J. Agric. Econ. 1997, 79, 1013-1023. [CrossRef]

10. Samples, K.C.; Hollyer, J.R. Contingent valuation of wildlife resources in the presence of substitutes and complements. In Economic Valuation of Natural Resources: Issues, Theory and Application, 1st ed.; Johnson, R.L., Johnson, V.G., Eds.; Westview Press: Boulder, CO, USA, 1989; pp. 177-192.

11. Whitehead, J. Ex ante willingness to pay with supply and demand uncertainty: Implications for valuing a sea turtle protection program. Appl. Econ. 1992, 24, 981-988. [CrossRef]

12. Loomis, J.B.; Larson, D. Total economic values of increasing gray whale populations: Results from a contingent valuation survey of visitors and households. Mar. Resour. Econ. 1994, 9, 275-286. [CrossRef]

13. Giraud, K.; Turcin, B.; Loomis, J.; Cooper, J. Economic benefit of the protection program for the Steller sea lion. Mar. Policy 2002, 26, 451-458. [CrossRef]

14. Jin, J.; Indab, A.; Nabangchang, O.; Thuy, T.D.; Harder, D.; Subade, R.F. Valuing marine turtle conservation: A cross-country study in Asian cities. Ecol. Econ. 2010, 69, 2020-2026. [CrossRef]

15. Boxall, P.C.; Adamowicz, W.L.; Olar, M.; West, G.E.; Cantin, G. Analysis of the economic benefits associated with the recovery of threatened marine mammal species in the Canadian St. Lawrence Estuary. Marine Policy 2012, 36, 189-197. [CrossRef]

16. Lim, S.Y.; Jin, S.J.; Yoo, S.H. The economic benefits of the Dokdo Seals restoration project in Korea: A contingent valuation study. Sustainability 2017, 9, 968. [CrossRef]

17. Cazabon-Mannette, M.; Schuhmann, P.W.; Hailey, A.; Horrocks, J. Estimates of the non-market value of sea turtles in Tobago using stated preference techniques. J. Environ. Manag. 2017, 192, 281-291. [CrossRef] [PubMed]

18. Habb, T.C.; McConnell, K.E. Valuing Environmental and Natural Resources; Edward Elgar: Cheltenham, UK, 2002.

19. Brent, R.J. Applied Cost-Benefit Analysis, 2nd ed.; Edward Elgar: Cheltenham, UK, 2006.

20. Varian, H.R. Intermediate Microeconomics: A Modern Approach, 9th ed.; W. W. Norton \& Company: New York, NY, USA, 2014.

21. Freeman III, A.M.; Herriges, J.A.; Kling, C.L. The Measurement of Environmental and Resource Values: Theory and Methods, 3rd ed.; Routledge: New York, NY, USA, 2014.

22. Garrod, G.; Willis, K.G. Economic Valuation of the Environment; Edward Elgar: Cheltenham, UK, 1999.

23. Mitchell, R.C.; Carson, R.T. Using Surveys to Value Public Goods: The Contingent Valuation Method; Resources for the Future: Washington, DC, USA, 1989.

24. Kim, J.H.; Kim, H.J.; Yoo, S.H. Willingness to pay for fuel-cell electric vehicles in South Korea. Energy 2019, 174, 497-502. [CrossRef]

25. Lim, S.Y.; Kim, H.J.; Yoo, S.H. Assessing the external benefits of contaminated soil remediation in Korea: A choice experiment study. Environ. Sci. Pollut. Res. 2018, 25, 17216-17222. [CrossRef] [PubMed] 
26. Kim, J.H.; Yoo, S.H. South Koreans' perspective on assisting the power supply to North Korea: Evidence from a contingent valuation. Energy Policy 2020, 139, 111336. [CrossRef]

27. Rodella, I.; Madau, F.A.; Carboni, D. The willingness to pay for beach scenery and its preservation in Italy. Sustainability 2020, 12, 1604. [CrossRef]

28. Bamwesigye, D.; Hlavackova, P.; Sujova, A.; Fialova, J.; Kupec, P. Willingness to pay for forest existence value and sustainability. Sustainability 2020, 12, 891. [CrossRef]

29. Just, R.E.; Hueth, D.L.; Schmitz, A. The Welfare Economics of Public Policy: A Practical Approach to Project and Policy Evaluation; Edward Elgar: Cheltenham, UK, 2004.

30. Venkatachalam, L. The contingent valuation method: A review. Environ. Impact Assess. Rev. 2004, $24,89-124$. [CrossRef]

31. Carson, R.T.; Hanemann, W.M. Contingent valuation. In Handbook of Environmental Economics: Valuing Environmental Changes; Maler, K.G., Vincent, J.R., Eds.; Elsevier: Amsterdam, The Netherlands, 2005; Volume 2, pp. 821-936.

32. Bigerna, S.; Polinori, P. The Economic Valuation of Green Electricity; Springer: Dordrecht, The Netherlands, 2018.

33. Fisher, A. The Conceptual Underpinnings of the Contingent Valuation Method. In The Contingent Valuation of Environmental Resources; Bjornstad, D.J., Kahn, J.R., Eds.; Edward Elgar: Cheltenham, UK, 1996; pp. $19-37$.

34. Arrow, K.; Solow, R.; Portney, P.R.; Leamer, E.E.; Radner, R.; Schuman, H. Report of the NOAA panel on contingent valuation. Fed. Regist. 1993, 58, 4601-4614.

35. Johnston, R.J.; Boyle, K.J.; Adamowicz, W.; Bennett, J.; Brouwer, R.; Cameron, T.A.; Hanemann, W.M.; Hanley, N.; Ryan, M.; Scarpa, R.; et al. Contemporary guidance for stated preference studies. J. Assoc. Environ. Resour. Econ. 2017, 4, 319-405. [CrossRef]

36. Hanemann, W.; Kanninen, B. The statistical analysis of discrete-response CV data. In Valuing Environmental Preferences: Theory and Practice of the Contingent Valuation Method in the US, EC and Developing Countries; Bateman, J., Willis, K.G., Eds.; Oxford University Press: Oxford, UK, 1996.

37. Hanemann, W.M. Welfare evaluations in contingent valuation experiments with discrete responses. Am. J. Agric. Econ. 1984, 66, 332-341. [CrossRef]

38. Hanemann, M.; Loomis, J.; Kanninen, B. Statistical efficiency of double-bounded dichotomous choice contingent valuation. Am. J. Agric. Econ. 1991, 73, 1255-1263. [CrossRef]

39. Cooper, J.C.; Hanemann, M.; Signorello, G. One-and-one-half bound dichotomous choice contingent valuation. Rev. Econ. Stat. 2002, 84, 742-750. [CrossRef]

40. McFadden, D. Contingent valuation and social choice. Am. J. Agric. Econ. 1994, 76, 689-708. [CrossRef]

41. Cooper, J.C.; Hanemann, W.M. Referendum Contingent Valuation: How Many Bounds are Enough? Working Paper; USDA Economic Research Search Service, Food and Consumer Economics Division: Washington, DC, USA, 1995.

42. Krinsky, I.; Robb, A.L. On approximating the statistical properties of elasticities. Rev. Econ. Stat. 1986, 68, 715-719. [CrossRef]

43. Statistics Korea. Korea Statistical Information Service. Available online: http://kosis.kr (accessed on 5 February 2020).

44. Kim, J.; Lim, S.Y.; Yoo, S.H. Measuring the economic benefits of designating Baegnyeong Island in Korea as a marine protected area. Int. J. Sustain. Dev. World Ecol. 2017, 24, 205-213. [CrossRef]

45. Lee, M.K.; Kim, J.H.; Yoo, S.H. Public willingness to pay for increasing photovoltaic power generation in Korea. Sustainability 2018, 10, 1196. [CrossRef]

46. Jorgensen, B.; Syme, G.; Bishop, B.; Nancarrow, B. Protest responses in contingent valuation. Environ. Resour. Econ. 1999, 14, 131-150. [CrossRef]

47. Pennington, M.; Gomes, M.; Donaldson, C. Handling protest responses in contingent valuation surveys. Med Decis. Mak. 2017, 37, 623-634. [CrossRef]

(C) 2020 by the authors. Licensee MDPI, Basel, Switzerland. This article is an open access article distributed under the terms and conditions of the Creative Commons Attribution (CC BY) license (http://creativecommons.org/licenses/by/4.0/). 